\title{
Adapting in the COVID-19 Era
}

Georgios Papathanakos ${ }^{1}$, Ioannis Andrianopoulos ${ }^{2}$, Athanasios Papathanasiou ${ }^{3}$, Dimitra Lepida ${ }^{4}$, Vasilios Koulouras ${ }^{5}$

Keywords: COVID-19, Face shield, Mask, Personal protective equipment, SARS-CoV-2.

Indian Journal of Critical Care Medicine (2020): 10.5005/jp-journals-10071-23689

\section{Dear Editor,}

While the COVID-19 epidemic flared up in nearby Italy, ${ }^{1}$ our intensive care unit (ICU) team started preparing for the COVID19 pandemic with a series of constructions and innovations: our high dependency unit was quickly equipped with ventilators, beds, and monitors. A glass/aluminum dividing wall was installed creating an anteroom and separating the nursing desk < green $>$ area from patients' $<$ red $>$ area allowing continuous visual inspection of patients and central station monitors without the need for personal protective equipment (PPE) (Fig. 1). This saved PPE resources and limited also medical and nursing-exposure time to COVID-19 patients. In addition, recommended negative

\author{
${ }^{1-5}$ Department of Intensive Care Unit, University Hospital of loannina, \\ Ioannina, Epirus, Greece
}

Corresponding Author: Ioannis Andrianopoulos, Department of Intensive Care Unit, University Hospital of Ioannina, Ioannina, Epirus, Greece, Phone: +3026510992012, e-mail: jandri0@yahoo.gr

How to cite this article: Papathanakos G, Andrianopoulos I, Papathanasiou A, Lepida D, Koulouras V. Adapting in the COVID-19 Era. Indian J Crit Care Med 2020;24(12):1286-1287.

Source of support: Nil

Conflict of interest: None
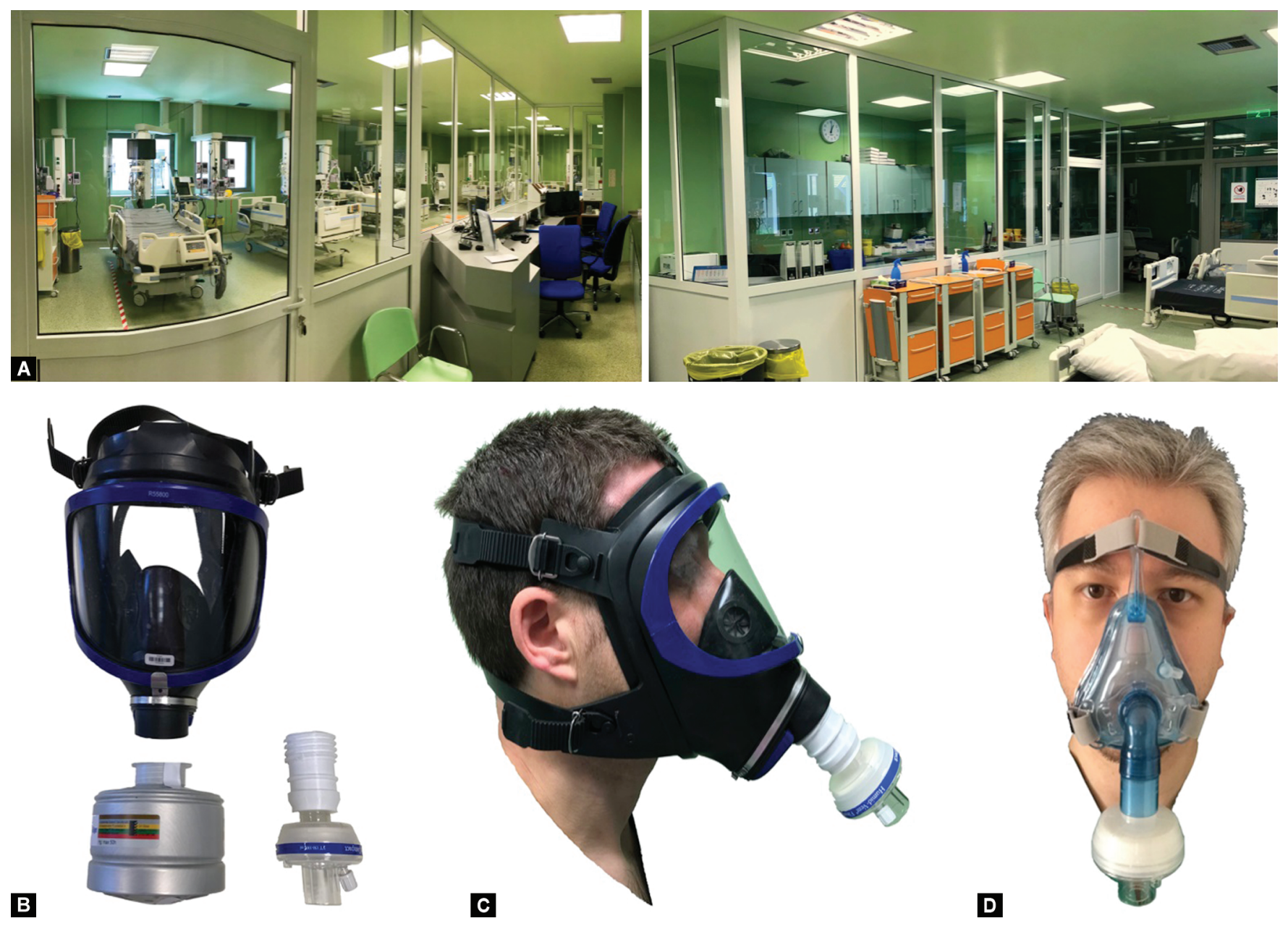

D

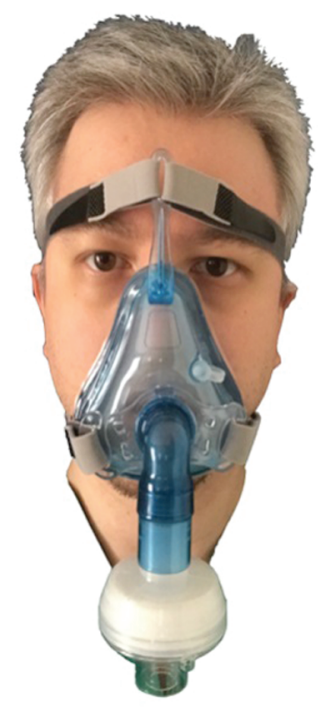

Figs 1 A to D: (A) Inside (left) and outside (right) view of the glass/aluminum dividing wall installed; (B) Industry full face mask with inherent P3 filter and our custom-made 3D-printed adaptor connected to a breathing circuit filter for mechanical ventilators; (C) View of the mask as used by our staff; (D) The noninvasive ventilation mask connected to a breathing circuit filter for mechanical ventilators as used by our staff

(0) The Author(s). 2020 Open Access This article is distributed under the terms of the Creative Commons Attribution 4.0 International License (https://creativecommons. org/licenses/by-nc/4.0/), which permits unrestricted use, distribution, and non-commercial reproduction in any medium, provided you give appropriate credit to the original author(s) and the source, provide a link to the Creative Commons license, and indicate if changes were made. The Creative Commons Public Domain Dedication waiver (http://creativecommons.org/publicdomain/zero/1.0/) applies to the data made available in this article, unless otherwise stated. 
pressure inside patients' care area was applied by making alterations in the ventilating system of the unit. More specifically, exhaust airflow was maximized, while the fresh air supply was reduced creating a negative pressure balance between the main patient area and the anteroom as well as between the anteroom and the rest of the unit. In addition, a HEPA filter was installed to filter exhaust room air before it is discharged outside. Negative pressure was regularly monitored initially daily and then once a week using a smoke test.

Due to FFP2/FFP3 mask limited supplies alternative options were sought; finally, we came up with two alternatives: the first one was the utilization of reusable elastomeric industry full face masks (NIOSH approved) with inherent reusable industry P3 filters. Due to the emergent need for repeated use by different ICU team members CDC crisis capacity strategy ${ }^{2}$ and the risk of contamination from inappropriate disinfection of the P3 filters we have 3D-printed a custom-made adaptor allowing industry-standard Rd40 connection with the low-cost, single-use and widely-used in anesthesia and ICU, heat-and-moisture-exchange (HME) breathing circuit filter (HME filter can provide up to $99.99 \%$ anti-viral protection). These masks proved easy to "don" and "doff", presented no fogging or air leakage and their only disadvantage was that staff had to speak louder to be heard clearly. Masks were disinfected using either a sodium hypochlorite solution or Incidin ${ }^{\circledast}$ Rapid Disinfectant.

Our second idea was to combine noninvasive ventilation masks equipped with soft silicone face seal strip, with the readily available HME breathing circuit filter in the inspiratory/expiratory connector, an idea that originally came from Boston Children's Hospital's Surgical Innovation Fellowship. ${ }^{3}$

Moreover, because of initial reports of shoe contamination from COVID-SARS- $2^{4}$ and lack of shoe covers, we bought closed rubber shoes from a local retailer normally utilized in stock-farming. For reducing virus contamination, we sprayed them during doffing with sodium hypochlorite solution and utilized sodium hypochloritewetted floor rugs between clean and contaminated zones.

Also, due to the very limited supply of eye protection equipment (goggles and face shields), available used goggles were collected during "doffing", were sent for plasma sterilization, or disinfected with sodium hypochlorite solution, and then they were re-used. The supply of face shields was even more limited. Initially, we bought re-usable face shields used in the industry and disinfected them with sodium hypochlorite solution. Later, we designed plastic face shields which were 3D-printed and supplied by the local industry. At this point, it must be stated that all the above-mentioned innovations should not be considered as standard practice and should be used only in cases of non-availability of standard devices and their parts.

Apart from the technical innovations, we had to adapt our practices as well: nursing care work was clustered, reducing PPE equipment usage and limiting the exposure time of staff inside the patient area; an apneic tracheostomy technique was improvised for patients requiring tracheostomy. Finally, due to increased demand and limited supply of resources for continuous renal replacement therapy (RRT), we performed alternately high dose intermittent RRT for 8 hours in each patient. In the COVID-19 era, each ICU needs to prepare, plan, and adapt. In this everyday fight, we need to implement all our human innovating abilities.

\section{References}

1. Livingston E, Bucher K. Coronavirus disease 2019 (COVID19) in Italy. JAMA 2020;323(14):1335. DOI: 10.1001/jama.2020. 4344.

2. Centers for Disease Control and Prevention. 2020. Coronavirus Disease 2019 (COVID-19). [online] Available at: <https://www.cdc. gov/coronavirus/2019-ncov/hcp/elastomeric-respirators-strategy/ index.html $>$ [Accessed 8 September 2020].

3. Surgical Innovation Fellowship. COVID-19: Our response to the N95 shortage. https://www.childrenshospital.org/research/departmentsdivisions-programs/departments/surgery/surgical-innovationfellowship. Accessed 10 May 2020.

4. Ong SWX, Tan YK, Chia PY, Lee TH, Ng OT, Wong MSY, et al. Air, surface environmental, and personal protective equipment contamination by severe acute respiratory syndrome coronavirus 2 (SARS-CoV-2) from a symptomatic patient. JAMA 2020;323(16):1610-1612. DOI: 1 0.1001/jama.2020.3227. 